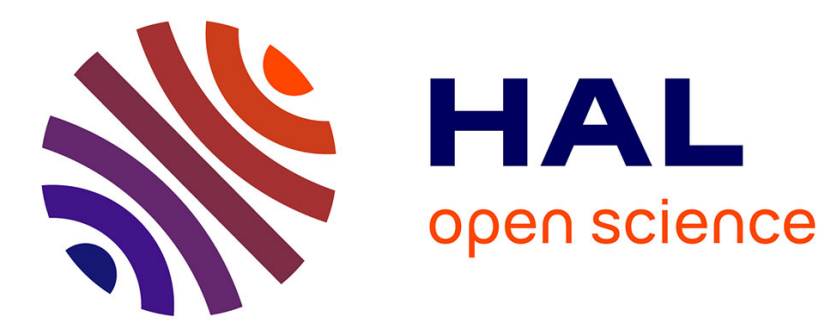

\title{
Tuning transport and magnetic properties of CoxFe3-xO4 thin films by Co content
} van Quang Nguyen, Yooleemi Shin, Anh Tuan Duong, Sunglae Cho, Christian Meny

\section{- To cite this version:}

van Quang Nguyen, Yooleemi Shin, Anh Tuan Duong, Sunglae Cho, Christian Meny. Tuning transport and magnetic properties of CoxFe3-xO4 thin films by Co content. Journal of Alloys and Compounds, 2019, 772, pp.1095-1099. 10.1016/j.jallcom.2018.09.007 . hal-02392331

\section{HAL Id: hal-02392331 \\ https://hal.science/hal-02392331}

Submitted on 14 Feb 2022

HAL is a multi-disciplinary open access archive for the deposit and dissemination of scientific research documents, whether they are published or not. The documents may come from teaching and research institutions in France or abroad, or from public or private research centers.
L'archive ouverte pluridisciplinaire HAL, est destinée au dépôt et à la diffusion de documents scientifiques de niveau recherche, publiés ou non, émanant des établissements d'enseignement et de recherche français ou étrangers, des laboratoires publics ou privés. 


\title{
Tuning transport and magnetic properties of $\mathrm{Co}_{x} \mathrm{Fe}_{3-\mathrm{x}} \mathrm{O}_{4}$
}

\section{thin films by Co content}

Van Quang Nguyen ${ }^{1}$, Yooleemi Shin ${ }^{2}$, Duong Anh Tuan ${ }^{1}$, Sunglae Cho ${ }^{1 *}$, and Christian

$$
M e n y^{2}
$$

${ }^{1}$ Department of Physics and Energy Harvest Storage Research Center, University of Ulsan, Ulsan 680-749, Republic of Korea

${ }^{2}$ Institute of Physics and Chemistry for Materials of Strasbourg, UMR 7504 UDS-CNRS, Strasbourg 67034, France

\begin{abstract}
We systematically investigated the influence of the Co content on the magnetic and transport properties of spinel $\mathrm{Co}_{\mathrm{x}} \mathrm{Fe}_{3-\mathrm{x}} \mathrm{O}_{4}(0 \leq \mathrm{x} \leq 1)$ thin films on $\mathrm{MgO}(001)$ substrates prepared by molecular beam epitaxy. Our films exhibited the spinel structure as expected. The Verwey transition was clearly observed in $\mathrm{Fe}_{3} \mathrm{O}_{4}$ and $\mathrm{Co}_{0.6} \mathrm{Fe}_{2} \mathrm{O}_{4}$, while it disappeared with higher $\mathrm{Co}$ contents. Electrical resistivity increased with the Co content from $0.003 \Omega$-cm for $\mathrm{x}=0$ to 1.5 $\Omega$-cm for $\mathrm{x}=1$ at $300 \mathrm{~K}$. As expected, magnetization curves show an increase of the coercive fields of the samples with the Co content. In addition, the samples reveal complex magnetic properties that are explained by a reorientation of the anisotropy easy axis from the crystal (111) directions to the (100) directions with the Co content.
\end{abstract}

\footnotetext{
${ }^{1}$ Electric email: slcho@ulsan.ac.kr
} 


\section{Highlights:}

1. We have successfully grown the epitaxial spinel $\mathrm{Co}_{\mathrm{x}} \mathrm{Fe}_{3-\mathrm{x}} \mathrm{O}_{4}(0 \leq \mathrm{x} \leq 1)$ thin films on $\mathrm{MgO}(001)$.

2. We observed the tunable transport and magnetic properties by controlling the Co content.

3. Verwey transition temperature was shifted from $105 \mathrm{~K}$ in $\mathrm{Fe}_{3} \mathrm{O}_{4}$ to $115 \mathrm{~K}$ in $\mathrm{Co}_{0.6} \mathrm{Fe}_{2} \mathrm{O}_{4}$, while it disappeared with higher Co content. The electrical resistivity increased with Co content.

4. We observed a shoulder in M-H curves in the samples $\mathrm{x}=0.6$ and 0.8 .

Keywords: Magnetic, $\mathrm{Fe}_{3} \mathrm{O}_{4}, \mathrm{CoFe}_{2} \mathrm{O}_{4}, \mathrm{MBE}$, Spinel

PACS: 75.30.Cr, 75.30.Gw, 75.47.Lx, 75.50.Gg 


\section{INTRODUCTION}

The first magnetic material, magnetite $\mathrm{Fe}_{3} \mathrm{O}_{4}$, discovered and used during Ancient Greece, still attracts attentions because of its puzzling properties. It is a ferrimagnet with an inverse spinel structure (lattice constant, a = $8.397 \AA$ Å), showing half-metallic nature and high Curie temperature $\left(\mathrm{T}_{\mathrm{C}}\right)$ up to $850 \mathrm{~K}$. This material has a first order metal-insulator transition at 120 $\mathrm{K}$, called Verwey transition. The inverse spinel crystal structure of $\mathrm{Fe}_{3} \mathrm{O}_{4}$ can be expressed as $\left[\mathrm{Fe}^{3+}\right]_{\mathrm{A}}\left[\mathrm{Fe}^{2+} \mathrm{Fe}^{3+}\right]_{\mathrm{B}} \mathrm{O}_{4}$, where $\mathrm{A}$ denoted the tetrahedrally coordinated $\mathrm{Fe}^{3+}$ (A-site) and $\mathrm{B}$ denoted the octahedral sites (B-site) [1]. The ferrimagnetism in $\mathrm{Fe}_{3} \mathrm{O}_{4}$ is due to the antiparallel alignment of the magnetic moments between the two B cations and the single A cation. The electrical conduction in ferrite originates from the superposition of two transport mechanisms, small-polaron (sp) band and sp hopping conduction [2]. Recently, researchers have focused on mixed ferrite, especially with $3 \mathrm{~d}$ transition metal such as $\mathrm{Co}, \mathrm{Mn}, \mathrm{Zn}, \mathrm{Ni}, \mathrm{Cu}$ and $\mathrm{Cr}$. It has been reported that the di-valances like $\mathrm{Cr}^{2+}$ and $\mathrm{Mn}^{2+}$ tend to occupy the $\mathrm{A}$ sites, while ions $\mathrm{Mg}^{2+}, \mathrm{Co}^{2+}, \mathrm{Ni}^{2+}$ and $\mathrm{Cu}^{2+}$ tend to occupy the B sites in the inverse spinel structure $[3,4]$. Among them, Co has very large magneto-crystalline anisotropy, which is expected to be of interest because the replacement of Fe ions by Co ions will not only affect the transport properties but also the magnetic properties of ferrite. The fraction of divalent cations that reside on the octahedral site was defined as inverse parameter, $\lambda$, where $\lambda=0$ for normal spinel and 1 for inverse spinel; for example, in $\mathrm{CoFe}_{2} \mathrm{O}_{4}, \lambda$ ranges from 0.76 to 0.98 [5]; for random distribution between two kinds of site, $\lambda=0.67$ [4]. Mössbeauer spectra of $\mathrm{CoFe}_{2} \mathrm{O}_{4}$ supported $\lambda=0.67$ [6] and Rahman et al. estimated $\lambda=0.54$ [7]. This inverse parameter has a strong effect on the electrical and magnetic properties of bulk ferrite [8]. $\mathrm{CoFe}_{2} \mathrm{O}_{4}$ has been widely used in applications such as magnetic recording, magnetic stress sensors, spin filtering, millimeter-wave filters, telecommunication equipment, and bio-molecular drug delivery [8-11], etc. There were several reports on the influence of Co concentration to the 
physical properties of ferrite. However, to the best of our knowledge, the systematic study of the effects of large Co content on the transport and magnetic properties in epitaxial ferrite thin films has not been reported.

In this paper, we report on the influence of Co content on the magnetic and transport properties of spinel $\mathrm{Co}_{\mathrm{x}} \mathrm{Fe}_{3-\mathrm{x}} \mathrm{O}_{4}(0 \leq \mathrm{x} \leq 1)$ thin films. With the increase of Co content the Verwey metal-insulator transition of $\mathrm{Fe}_{3} \mathrm{O}_{4}$ was shifted to higher temperature and eventually disappeared with large Co content. With increasing Co concentration the electrical resistivity can be tuned over 3 orders of magnitude. Coercive field increased, while saturation magnetization decreased with Co content. More surprisingly a non-zero remanence is observed in the out of plane magnetization curves. This is attributed to an enhancement of the out of plane magnetic anisotropy due to the strains in the films.

\section{EXPERIMENT}

$\mathrm{Co}_{\mathrm{x}} \mathrm{Fe}_{3-\mathrm{x}} \mathrm{O}_{4}(\mathrm{x}=0.0,0.6,0.8$, and 1.0$)$ thin films were epitaxially grown on $\mathrm{MgO}(001)$ substrates by MBE (VG Semicon, Inc.). The MgO substrate was initially cleaned with methanol before being loaded into the vacuum chamber. After pre-heating at $600{ }^{\circ} \mathrm{C}$ for 30 minutes in ultra-high vacuum (UHV), the substrate was cooled down to $400{ }^{\circ} \mathrm{C}$, and maintained at that temperature during the growth. The base pressure of the growth chamber was $\sim 10^{-9}$ Torr. Atomic oxygen gas was then applied using an oxygen cracking cell. The films were grown by the co-deposition of $\mathrm{Co}$ and Fe using effusion cells under an oxygen partial pressure of $10^{-6}$ Torr. The evaporation rates were determined using a quartz crystal thickness monitor. The expected film thickness was $200 \mathrm{~nm}$. The quality of the films was monitored by in-situ reflection high energy electron diffraction (RHEED). The crystal structure of the samples was characterized by X-ray diffraction (XRD). The composition of films was determined after deposition by electron probe micro-analyzer (EPMA). A four- 
probe Van der Pauw configuration was employed to measure electrical resistivity. The charge carrier type in the samples was deduced from the slope of $\Delta \mathrm{V} v s \Delta \mathrm{T}$ curves using a differential method. The magnetic properties of the films have been examined in-plane and out-of-plane by an alternating gradient field magnetometer (AGFM) and a superconducting quantum interference device (SQUID) magnetometer (Quantum Design, Inc.) with the applied magnetic field up to 25 and $75 \mathrm{kOe}$, respectively.

\section{RESULT AND DISCUSSION}

Figure 1 shows the RHEED patterns of the $\mathrm{Co}_{x} \mathrm{Fe}_{3-\mathrm{x}} \mathrm{O}_{4}$ films along the [100] azimuth taken after film growth. The cleaned $\mathrm{MgO}$ substrate showed a good RHEED pattern with Kikuchi lines, as shown in the inset of Fig. 1 (a). Streaky RHEED patterns were observed in all samples, indicating the epitaxial growth and smooth surface of the samples on $\mathrm{MgO}$ substrate. The pattern also indicated a surface reconstruction in our films. The relation between lattice constant of a crystal and its RHEED lines spacing is expressed as

$$
a \sim \frac{1}{d}
$$

where $a$ is $a$-axis lattice constant of the crystal and $d$ is the RHEED lines spacing. Based on the relation (1), we may estimate the lattice constant of the film with standard error of $0.1 \%$. The lines spacing of $\mathrm{MgO}$ is two times larger than that of the films, indicating the double lattice constant of the films compared to that of the substrate in agreement with theoretical values.

The crystalline structures of the $\mathrm{Co}_{\mathrm{x}} \mathrm{Fe}_{3-\mathrm{x}} \mathrm{O}_{4}$ films on $\mathrm{MgO}$ (001) substrate were examined by $\theta-2 \theta$ scan XRD experiment, as illustrated in Fig. 2. All films exhibited a single phase with an excellent crystalline quality on $\mathrm{MgO}(001)$ substrate, which can be indexed in a spinel structure. With the presence of Co, there is a slight shift of (008) peaks toward to the 
right. The lattices constants were calculated from (008) peaks; 8.365, 8.357, 8.360, and 8.360 $\AA$ for samples $x=0.0,0.6,0.8$, and 1.0 , respectively. These values indicated a decrease of lattice constants with the presence of Co. Compared to the bulk values of $\mathrm{Fe}_{3} \mathrm{O}_{4}(8.397 \AA)$ and $\mathrm{CoFe}_{2} \mathrm{O}_{4}(8.388 \AA$ ), our films exhibited tensile strains; $0.38 \%$ and $0.36 \%$ for $\mathrm{x}=0.0$ and $\mathrm{x}=1.0$, respectively. These observations are consistent with the substitution of Co into Fe site because of the smaller atomic radius of Co $(135 \mathrm{pm})$ compared to the one of Fe (140 pm) [12].

Figure 3(a) shows the effects of Co doping content on the electrical resistivity of $\mathrm{Co}_{\mathrm{x}} \mathrm{Fe}_{3-\mathrm{x}} \mathrm{O}_{4}$ in the temperature range from $410 \mathrm{~K}$ down to $85 \mathrm{~K}$, which is below the Verwey transition temperature of $\mathrm{Fe}_{3} \mathrm{O}_{4}$. For all samples the electrical resistivity decreased with increasing temperature. The introduction of Co atoms into ferrite shows an increasing electrical resistivity over three orders of magnitude from $0.003 \Omega \cdot \mathrm{cm}$ for $\mathrm{x}=0.0$ to $1.5 \Omega \cdot \mathrm{cm}$ for $\mathrm{x}=$ 1.0 at $300 \mathrm{~K}$. A Verwey transition was clearly observed in the $\mathrm{Fe}_{3} \mathrm{O}_{4}$ at around $105 \mathrm{~K}$ in agreement with previous report $[\mathbf{1 3}, \mathbf{1 4}]$. The observation of a Verwey transition also confirmed the high quality of our un-doped film. With the introduction of small Co content, the Verwey transition temperature increases up to $115 \mathrm{~K}$ in the $\mathrm{Co}_{0.6} \mathrm{Fe}_{3} \mathrm{O}_{4}$ film. On the other hand, the Verwey transition was not observed for higher Co contents. The conduction in ferrites can be explained by hopping models, where the electrical conduction of ferrite is dominated by electron hopping between $\mathrm{Fe}^{2+}$ and $\mathrm{Fe}^{3+}$ cations present at octahedral $\mathrm{B}$ sites. Hopping rate increases with temperature due to the increase in thermal energy compared to the hopping barrier height [15]. In contrast, in $\mathrm{CoFe}_{2} \mathrm{O}_{4}$ electron hopping is not possible anymore and electron conduction can only occur by thermal activation of electrons from the valance band to the conduction ban. Therefore, the resistivity mainly depends on the size of band gap. J. A. Moyer et al. [5] reported that when doping $\mathrm{CoFe}_{2} \mathrm{O}_{4}$ with Fe the introduction of $\mathrm{Fe}^{2+}$ ions produces an increase of the density of states at the fermi level resulting in a shift of the Fermi level with respect to the top of the valance band. In summary the resistivity 
measurements show that the replacement of $\mathrm{Fe}$ ions by $\mathrm{Co}$ ions results in an increase in electrical resistivity originating from the gradual suppression of the electron hopping mechanism, and in a shift and eventually the disappearance of Verwey transition Interestingly, a transition in the temperature dependent resistivity was observed at $365 \mathrm{~K}$ in $\mathrm{CoFe}_{2} \mathrm{O}_{4}$ as shown in Fig. 3 (a). Note that in bulk form, $\mathrm{CoFe}_{2} \mathrm{O}_{4}$ exhibited no transition above room temperature [16]. However, a similar transition has been reported in the $\mathrm{CoFe}_{2} \mathrm{O}_{4}$ nanostructures around $330 \mathrm{~K}$ [7] and $370 \mathrm{~K}$ [17] assigned to a semiconductor to metallic transition. These authors interpreted this transition by the coexistence of cation-anion-cation $(\mathrm{c}-\mathrm{a}-\mathrm{c})$ and cation-cation (c-c) interaction in rock-salt-structures.

Figure 3(b) shows the temperature dependent Seebeck coefficient. The sign of the Seebeck coefficient was negative, indicating dominant n-type conduction. The Seebeck coefficient increase with the increase in Co concentration is consistent with the trend in electrical resistivity; from $-63 \mu \mathrm{V} / \mathrm{K}$ for $\mathrm{x}=0.0$ to $-215 \mu \mathrm{V} / \mathrm{K} \mathrm{cm}$ for $\mathrm{x}=1.0$ at $300 \mathrm{~K}$. A peak at $350 \mathrm{~K}$ was also observed in sample $\mathrm{CoFe}_{2} \mathrm{O}_{4}$ that is consistent with the transition already mentioned in the electrical resistivity.

In order to investigate the influence of the Co content on the magnetic properties of the ferrites we have measured the magnetization as a function of magnetic field using an AGFM set up. Figure 4 shows room temperature in-plane and out-of-plane M-H curves of our films. However, the AGFM maximum magnetic field is $25 \mathrm{kOe}$ and even if this field was large enough to reach the reversible part of the magnetization processes, it was not possible to fully saturate the magnetization of the samples. Therefore, the AGFM measurements were complemented by SQUID measurements in order to properly evaluate saturation magnetizations. The evolution of saturation magnetization versus Co content is shown in Fig. 4(c). Saturation magnetization is decreasing, with the Co content. The decrease of saturation magnetization with the Co content can be interpreted as following. The net 
magnetization of spinel ferrite can be given by $\mathrm{M}=\sum \mathrm{M}_{\mathrm{B} \text {-sites }}-\sum \mathrm{M}_{\mathrm{A} \text {-sites, }}$, where $\sum \mathrm{M}_{\mathrm{A} \text {-sites }}$ and $\sum \mathrm{M}_{\mathrm{B}-\text { sites }}$ are the contributions to the net magnetization by the cations on the tetrahedral $\mathrm{A}$ and octahedral B-sites, respectively [16]. The $\mathrm{Co}^{2+}$ ions (magnetic moment $3 \mu_{\mathrm{B}}$ ) in the Co-ferrite system tend to replace Fe ions (magnetic moment $4.9 \sim 6.7 \mu_{\mathrm{B}}$ ) in either the tetrahedral Asites or octahedral B-sites, resulting in an overall decrease in the total magnetic moment. The Fig. 4 (c) and (d) also show the evolution of the remnant magnetizations (Mr/Ms) and of the coercive fields as a function of the Co content. It is surprising that the out of plane remnant magnetizations and coercive fields are increasing with the Co content and eventually decrease again when $x=1$. In plane coercive fields only increase with the Co content. An increase of the coercive fields is expected with the introduction of Co because Co ions provide a strong contribution to the magneto crystalline anisotropy. The most likely explanation of the evolution of the out of plane remnant magnetizations and coercive fields is that a reorientation of the magneto crystalline anisotropy takes place with the Co content. Indeed, in bulk $\mathrm{Fe}_{3} \mathrm{O}_{4}$ the magnetic anisotropy easy axes are along the (111) directions while in bulk $\mathrm{CoFe}_{2} \mathrm{O}_{4}$ the magnetic anisotropy easy axes are along the (100) directions. When a small content of $\mathrm{Co}$ is introduced, the anisotropy is enlarged but the $\mathrm{Fe}_{3} \mathrm{O}_{4}$ magnetic anisotropy directions are not modified. Since the growth direction of the samples is (100), increasing the anisotropy along the (111) direction will result in an out of plane contribution of the magnetic anisotropy that overcomes (at least partly) the demagnetizing energy. This explains the increase of the out of plane remnant magnetizations and coercive fields until the Co content becomes large enough to allow a reorientation of the magnetic easy axes along the (100) directions. (100) directions are situated as well out of the film plane as in the film plane, therefore no out of plane contribution should be found and in such case out of plane remnant magnetizations and coercive fields should be negligible. Our experimental results show that in agreement with this description the remnant magnetization and out of plane coercive field 
decrease when $x=1$ but stay however significantly larger than zero. This might be due to an enhancement of the out of plane magnetic anisotropy due to the strains in the films that have been discussed in a previous paragraph. It can also be noticed that with the presence of Co, a shoulder is observed in sample $\mathrm{x}=0.6$ and more clearly in sample $\mathrm{x}=0.8$ but disappeared in sample $x=1.0$. Similar shoulders are observed in $\mathrm{CoFe}_{2} \mathrm{O}_{4} / \mathrm{Fe}_{3} \mathrm{O}_{4}$ bi-layer systems or in any bi-layer systems which consist of one soft and one hard magnetic layers [18 - 21]. However, we do not think that the observation of a shoulder in the magnetization curves of samples $\mathrm{x}=$ 0.6 and 0.8 is due to the coexistence of soft and hard magnetic phases since this would require a non-homogeneous distribution of the Co ions into the samples. The observation of this shoulder is probably related to the complex magnetic anisotropy orientations discussed above that might lead to complex magnetization reversal processes in samples in which canted and/or perpendicular anisotropy directions compete with demagnetizing field.

\section{CONCLUSION}

Through the Co content we have shown that it is possible to tune the magnetic and transport properties of epitaxial $\mathrm{Co}_{\mathrm{x}} \mathrm{Fe}_{3-\mathrm{x}} \mathrm{O}_{4}(0 \leq \mathrm{x} \leq 1)$ thin films. The Verwey metal-insulator transition was clearly shown in the samples with $\mathrm{x}=0.0$ and 0.6 but disappeared in the samples with $\mathrm{x}=0.8$ and 1.0. The electrical resistivity increased with the Co content and can be tailored over more than 3 orders of magnitude. A semiconductor to metallic transition was observed at $365 \mathrm{~K}$ in the $\mathrm{CoFe}_{2} \mathrm{O}_{4}$ film. The samples reveal complex magnetic properties that are explained by a reorientation of the anisotropy easy axis from the (111) directions to the (100) directions with the Co content. In summary the magnetic and transport properties of the films can be easily controlled by changing the Co concentration, indicating a possibility to incorporate $\mathrm{Co}_{\mathrm{x}} \mathrm{Fe}_{3-\mathrm{x}} \mathrm{O}_{4}$ films as ferromagnetic electrodes in spintronic devices. 


\section{ACKNOWLEDGEMENTS}

This research is also conducted within the context of the CNRS LIA "Functional nanostructures: morphology, nanoelectronics and ultrafast optics", NANOFUNC. This work was also supported by the National Research Foundation of Korea [NRF-2009-0093818 and NRF-2014R1A4A1071686]. 


\section{REFERENCES}

1. J. P. Wright, J. P. Attfield, and P. G. Radaelli, Phys. Rev. Lett. 87, 26 (2001).

2. D. Ihle and B. Lorenz, J. Phys. C: Solid State Phys. 18, L647 (1985).

3. D. Tripathy, A. O. Adeyeye, C. B. Boothroyd, and S. N. Piramanayagam, J. Appl. Phys. 101, 013904 (2007).

4. J. D. Dunitz and L. E. Orgel, J. Phys. Chem. Solids Pergamon Press 3, 318 (1957).

5. J. A. Moyer, C. A. F. Vaz, E. Negusse, D. A. Arena, and V. E. Henrich, Phys. Rev. B 83, $035121(2011)$

6. N. Moumen and M. P. Pileni, Chem. Mater. 8, 1128 (1996).

7. A. Rahman, M. A. Rafiq, S. Karim, K. Maaz, M. Siddique and M. M. Hasan, J. Phys. D: Appl. Phys. Lett. 44, 165404 (2011).

8. E. V. Gopalan, P. A. Joy, I. A. Al-Omari, D. S. Kumar, Y. Yoshida, M. R. Anantharaman, J. Alloys Compd. 485, 711 (2009).

9. Y. C. Mattei, O. P. Perez, M. S. Tomar, F. Roman, P. M. Voyles, and W. G. Stratton, J. Appl. Phys. 103, 07E512 (2008).

10. T. Saragi, N. Syakir, T. H. Nainggolan, C. Alboin, and Risdiana, AIP Conference Proceedings 1554, 123 (2013).

11. A. V. Ramos, J. B. Moussy, M. J. Guittet, M. G. Soyer, C. Gatel, P. B. Guillemaud, B. W. Fonrose, and E. Snoeck, Phys. Rev. B 75, 224421 (2007).

12. N. Viart, G. Rebmann, G. Pourroy, J. L. Loison, G. Versini, F. Huber, C. U. Bouillet, C. Meny, P. Panissod, and L. Saviot, Thin solid films 471, 40 (2005). 
13. D. Reisinger, P. Majewski, M. Opel, L. Alff, and R. Gross, Appl. Phys. Lett. 85, 4980 (2004).

14. E. J. W. Verwey, Nature 144, 327 (1939).

15. J. Smith and H. P. J. Wijn, Ferites. NewYork: Wiley, 1959, pp. 229-234.

16. I. C. Nlebedim, E. M. Levin, R. Prozorov, K. W. Dennis, R. W. McCallum, and D. C. Jiles, IEEE. Trans. Magn. 49, 389 (2013).

17. A. Arunkumar, D. Vanidha, K. Oudayakumar, S. Rajagopan, and R. Kannan, J. Appl. Phys. 114, 183905 (2013).

18. Michael G. Chapline and S. X. Wang, J. Appl. Phys. 97, 10C915 (2005).

19. Y. Suzuki, R. B. van Dover, E. M. Gyorgy, Julia M. Phillips, and R. J. Felder, Phys. Rev. B 53, 21 (1996).

20. A. V. Ramos, J. B. Moussy, M. J. Guittet, M. G. Soyer, C. Gatel, P. B. Guillemaud, Phys. Rev. B 75, 224421 (2007).

21. A. V. Ramos, S. Matzen, J. B Moussy, F. Ott, and M. Viret, Phys. Rev. B 79, 014401 (2009). 


\section{Figure captions}

FIG. 1 (Color online) RHEED patterns of $\mathrm{Co}_{\mathrm{x}} \mathrm{Fe}_{3-\mathrm{x}} \mathrm{O}_{4}$ thin films; (a) $\mathrm{x}=0.0$, (b) $\mathrm{x}=0.6$, (c) $\mathrm{x}=0.8$, and $(\mathrm{d}) \mathrm{x}=1.0$. The inset in Fig. 1 (a) is that of $\mathrm{MgO}$ substrate.

FIG. 2 (Color online) XRD patterns of $\mathrm{Co}_{\mathrm{x}} \mathrm{Fe}_{3-\mathrm{x}} \mathrm{O}_{4}$ thin films on the $\mathrm{MgO}(001)$ substrate at various Co concentrations; $\mathrm{x}=0.0, \mathrm{x}=0.6, \mathrm{x}=0.8$, and $\mathrm{x}=1.0$. All films show spinel crystal structure.

FIG. 3 (Color online) Temperature dependence of (a) electrical resistivity and (b) Seebeck coefficient with different Co concentrations; $\mathrm{x}=0.0,0.6$, and 0.8, and 1.0. The inset of Fig. 1(a) is a magnification of temperature dependent resistivity of sample $\mathrm{x}=1.0$.

FIG. 4 (Color online) (color online) Room temperature magnetic field dependent magnetization by AGFM for (a) in-plane and (b) out of plane for samples; $x=0.0,0.6,0.8$, and 1.0. (c) saturation magnetization taken from in-plane SQUID measurements and squareness ratio $M_{r} / M_{S}$ where $M_{r}$ is taken from AGFM measurements as a function of Co content. (d) in and out-of-plane coercive fields taken from AGFM measurements as a function of Co content. 
FIG. 1, Nguyen et al.

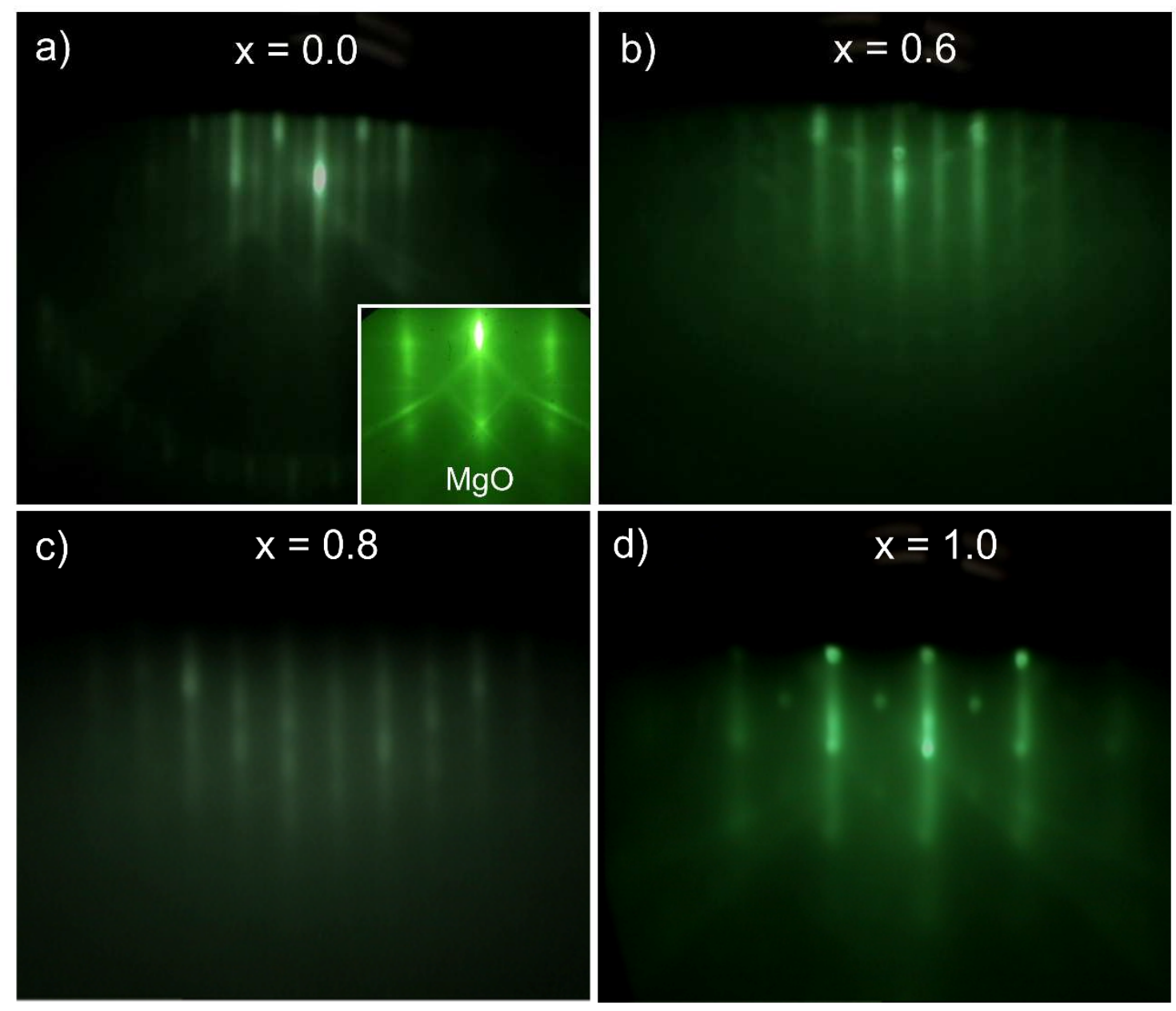


FIG. 2, Nguyen et al.

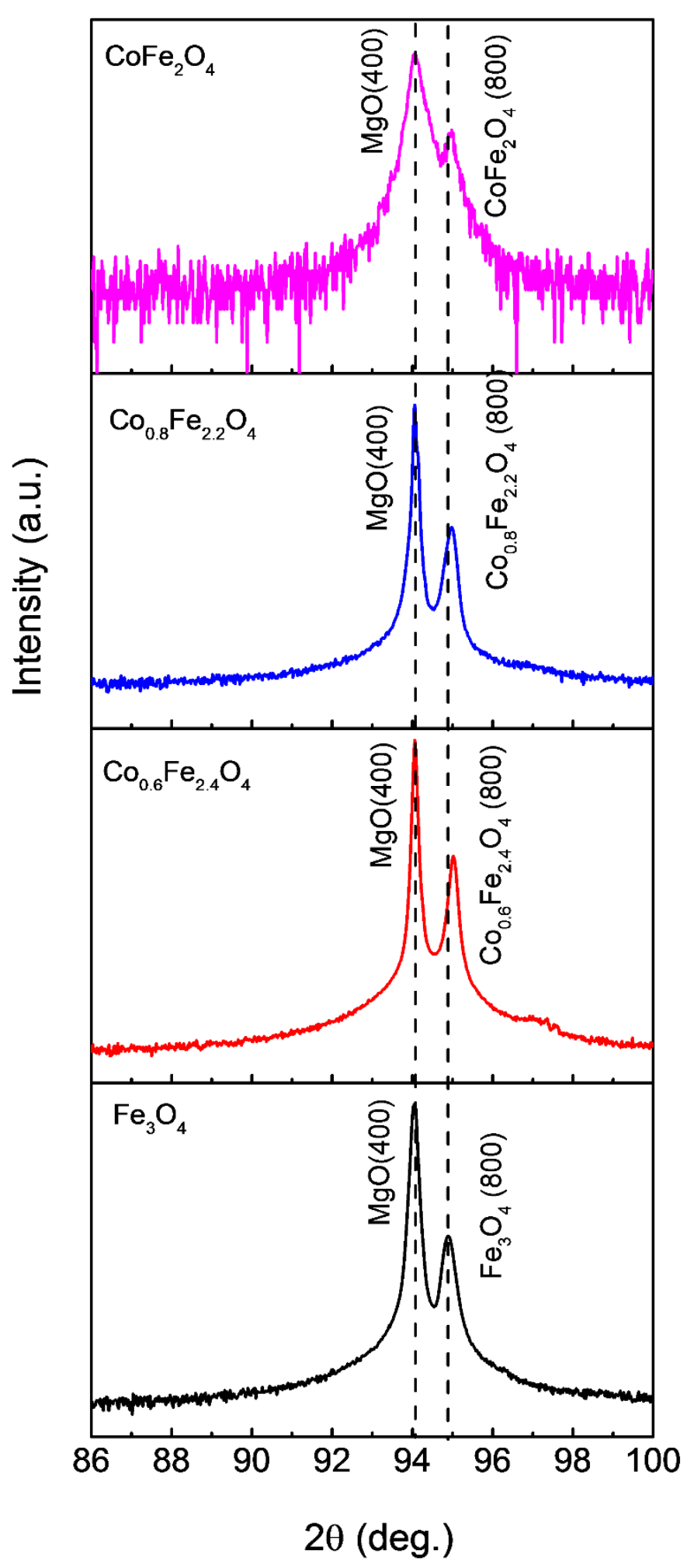


FIG. 3, Nguyen et al.

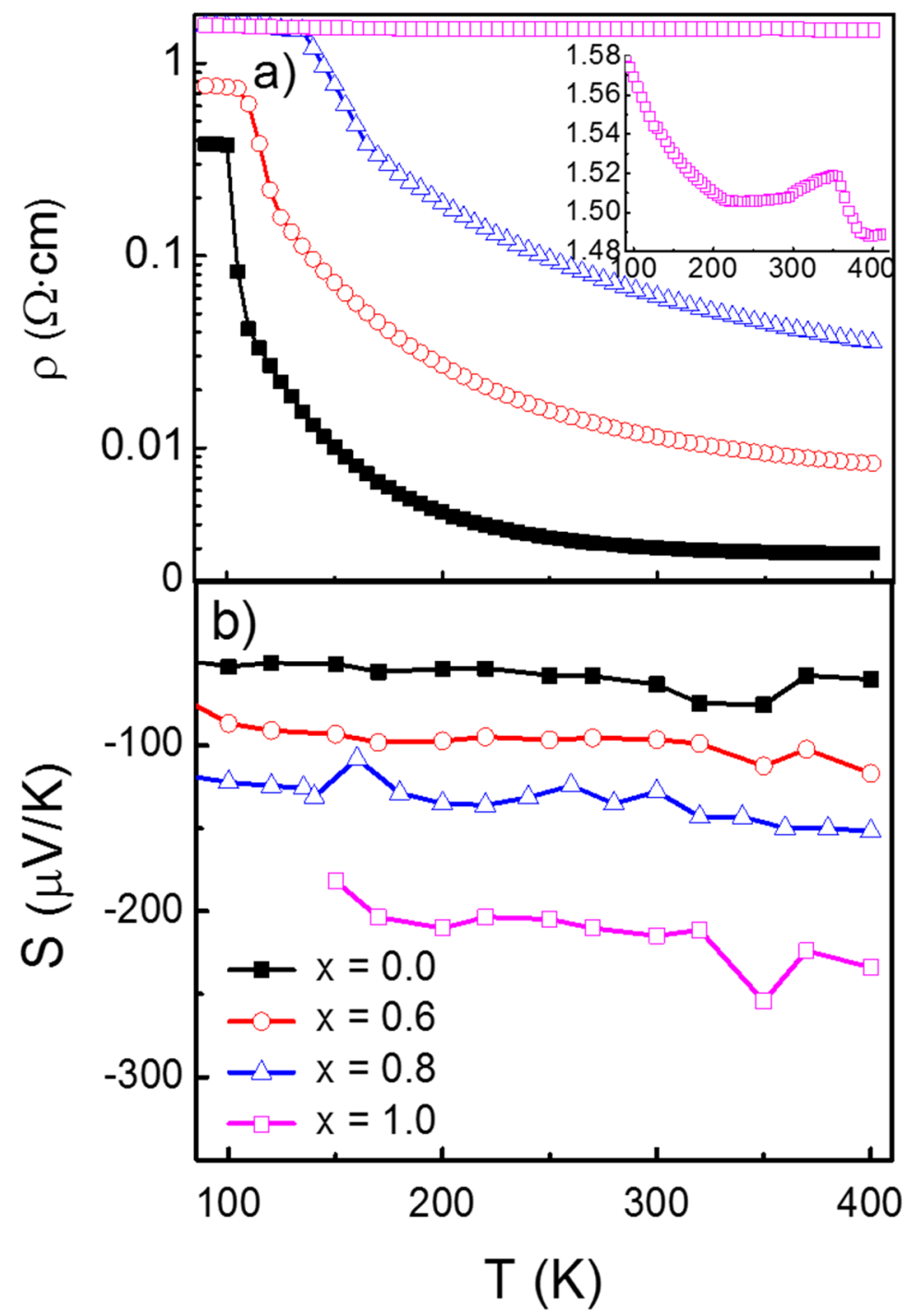


FIG. 4, Nguyen et al.
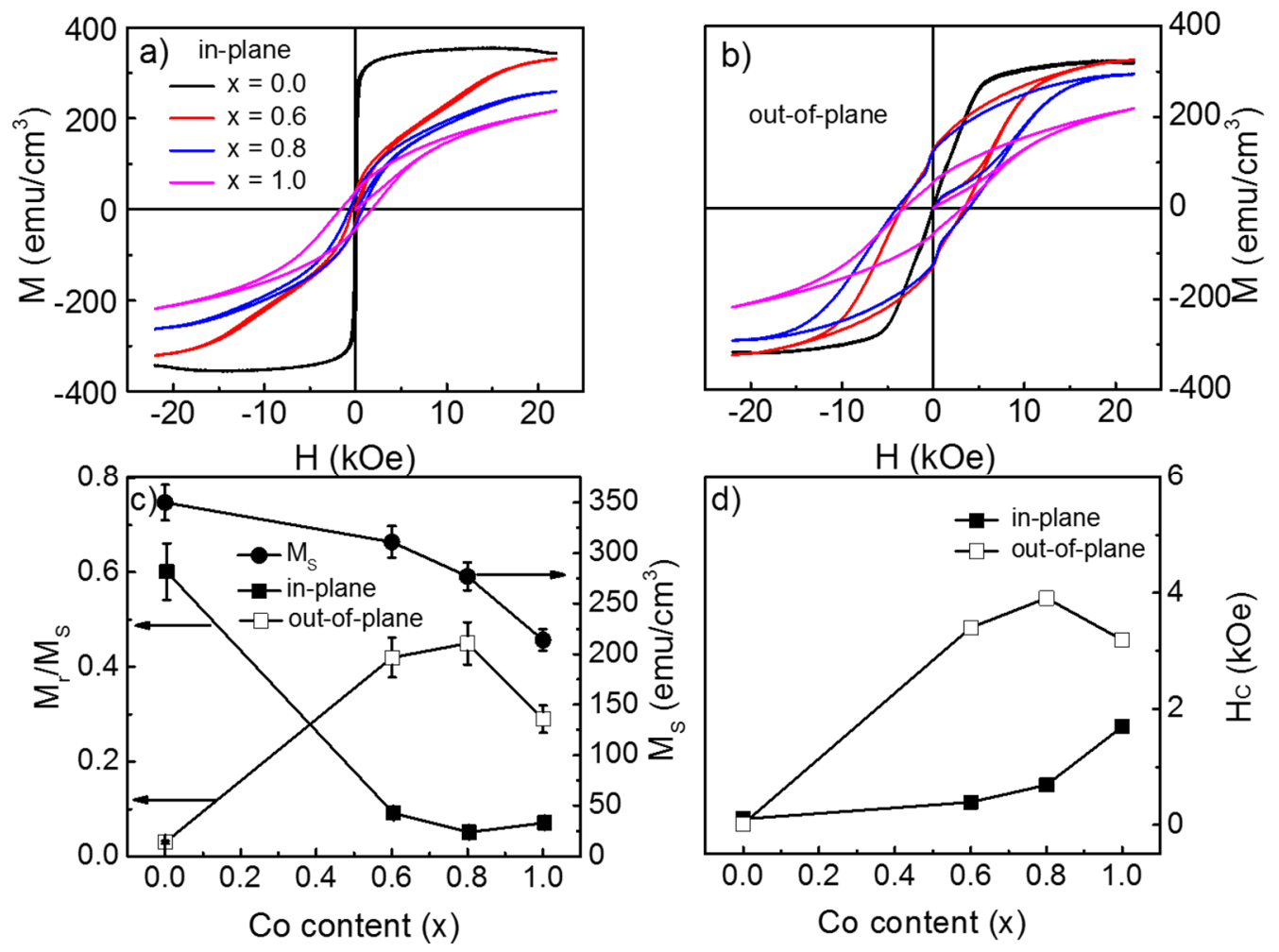